\title{
AS VÁRIAS FACES DE UM CRÍTICO LITERÁRIO: RECEPÇÃO ACADÊMICA DE ANTONIO CANDIDO EM TRÊS CONGRESSOS DE CIÊNCIAS SOCIAIS (2005-2017)
}

FARIA, Luis Gustavo de Paiva ${ }^{1}$ MOURÃO, Victor Luiz Alves ${ }^{2}$

RESUMO: A proposta do trabalho é explorar a recepção acadêmica, compreendida nos usos e apropriações da obra de Antonio Candido no debate contemporâneo em três congressos nacionais de Ciências Sociais. O texto se inspira em uma perspectiva teórico-metodológica proposta pelo próprio Candido, qual seja: a configuração de uma análise da produção intelectual segundo a tríade autor-obrapúblico. Procedeu-se a uma pesquisa bibliográfica de caráter quali-quantitativo que procura mapear a produção científica relacionada a Antonio Candido em grupos de variáveis fundamentais. A análise permitiu construir um padrão de recepção da obra do crítico literário que aponta para uma multiplicidade de apropriações, ainda que haja predominância de determinadas modalidades de uso e de obras referenciadas.

PALAVRAS-CHAVE: Antonio Candido, Sociologia dos Intelectuais, Sociologia da Literatura.

\section{THE VARIOUS FACES OF A LITERARY CRITIC: ACADEMICAL RECEPTION OF ANTONIO CANDIDO IN THREE SOCIAL SCIENCE CONGRESSES (2005-2017)}

\begin{abstract}
The purpose of this work is to explore the academical reception, intends in the uses and appropriations of Antonio Candido and his work in the contemporary debate in three national congresses of Social Sciences. The text is inspired by a theoretical-methodological perspective proposed by Candido himself, namely: the configuration of an analysis of intellectual production according to the author-work-public triad. A qualitative-quantitative bibliographical research was carried out to map the

\footnotetext{
${ }^{1}$ Graduando em Ciências Sociais pela Universidade Federal de Viçosa (UFV). Contato: lgpaivafaria@gmail.com. ${ }^{2}$ Professor Adjunto do Departamento de Ciências Sociais da Universidade Federal de Viçosa (DCS/UFV). Contato: vmourao@ufv.br.
} 
scientific production related to Antonio Candido in groups of fundamental variables. The analysis allowed to construct a pattern of appropriations of the author's oeuvre that points to a multiplicity of appropriations, although there are predominance of certain modalities and referenced works.

KEYWORDS: Antonio Candido, Sociology of Intellectuals, Sociology of Literature.

\section{INTRODUÇÃO}

A produção de bens culturais e obras artísticas se configuram como objeto de análise disputado por diversas áreas do conhecimento, as quais assumem diferentes perspectivas teóricas, analíticas e metodológicas que conformam distintamente o modo da apreensão científica dessa produção. Em nossa abordagem, assumimos o pressuposto de que, para compreender e interpretá-la, é necessário ultrapassar uma noção estritamente formalista de produções artísticas com o objetivo de alcançar uma perspectiva integrada que relacione aspectos contextuais, sociais e simbólicos como ponto de apoio para a produção, distribuição e recepção dessas produções e os contextos nos quais se inserem e exercem efeito. Desse modo, compreende-se que, assim como artistas e suas obras, cientistas e intelectuais e suas respectivas produções estão passíveis de apropriações a partir de uma recepção particularizada e relacionada a diversas variáveis sociais, como período histórico de produção, instituições acadêmicas de vinculação, interesses científicos e políticos (BECKER, 2010; BOURDIEU 1996, 2002, 2006; GEERTZ, 1997; MANNHEIM, 1952).

Neste trabalho, tomamos por objeto um pensador central na configuração do campo da crítica literária em nosso país: Antonio Candido, figura que pode ser caracterizada como multifacetada por (1) sua formação acadêmica multidisciplinar; (2) pelas áreas diversas em que concentra sua obra; e (3) pela recepção de sua obra em várias áreas do conhecimento. A caracterização feita por Mariza Peirano (1992, p. 25) capta ironicamente o espírito das facetas do autor: "Antonio Candido: sociólogo frustrado, antropólogo que se camuflou, crítico literário realizado? Qual o melhor retrato deste cientista social que, de maneira cautelosa, deixou sua marca em tantas áreas de conhecimento no Brasil?’. Se Drummond, poeta próximo a Candido (SANSEVERINO, 2008), se considera um "poeta de sete faces", como avaliar as várias faces que são dadas a um intelectual como Antonio Candido?

Do ponto de vista biográfico, sua atuação acadêmica foi concentrada na Universidade de São Paulo (USP), onde atuou entre as décadas de 1940 e 1990, passando pela graduação, 
pós-graduação e, posteriormente, atuando como professor e pesquisador, mesmo após sua aposentadoria, em um trânsito entre os distintos campos das Ciências Sociais, em particular a Sociologia e a Antropologia. É nesta interface que o trabalho que dá origem à sua tese de doutorado, Os Parceiros do Rio Bonito, se tornaria uma obra de referência na área por seu caráter e rigor teórico, empírico e político (SANTOS, 2002). Posteriormente se afirma sua inclinação à Teoria e Crítica Literária, tendo atuado como professor da área de Literatura Brasileira na Faculdade de Filosofia, Ciência e Letras de Assis, atualmente vinculada à Universidade Estadual Paulista (UNESP), entre os anos de 1958 e 1960.

Sua trajetória, marcada pelo pluralismo, permite posicionar o autor como uma das personalidades fundamentais do campo cultural e literário nacional (PEIRANO, 1992). Atuando na interface entre a sociologia da literatura e a crítica literária, contribuiu decisivamente para a consolidação destes campos de pesquisa no país e para a delimitação profissional das atividades de uma crítica literária acadêmica. Foi uma liderança no grupo que fundou a revista Clima e na geração que institucionalizou as Ciências Sociais nas universidades brasileiras (PONTES, 1988), sendo ainda criador de uma vasta obra e professor de mais de uma geração de especialistas atuando nesta fronteira entre crítica literária e sociologia, por um lado mantendo a trajetória da crítica social aliada à literatura feita em nosso país e, por outro, promovendo sua cientificização ao construir um modo de análise (crítica integrativa) que evitou recair nos pares analíticos opostos da autonomia estética plena da obra por um lado e, por outro, do "sociologismo" que predica à obra um reflexo da sociedade e de sua estrutura (CANDIDO, 2006; JACKSON, 2009; WAIZBORT, 2002).

A partir dessas considerações, a proposta deste texto é realizar uma exploração da recepção acadêmica de Antonio Candido, compreendida aqui nos usos e apropriações de sua obra no debate contemporâneo em três congressos nacionais da área de Ciências Sociais. Para isso, foram definidos critérios metodológicos que organizaram o levantamento do corpus empírico da pesquisa em variáveis de classificação que possibilitaram forjar uma tipologia das apropriações da obra do autor, caracterizando, assim, o modo pelo qual o campo acadêmico das Ciências Sociais apropria-se da obra de Candido.

Para cumprir esses objetivos, o texto será estruturado em quatro partes, além desta introdução: em um primeiro momento, discute-se os aportes teóricos que embasaram o tratamento e a análise dos dados produzidos; em uma segunda parte, explica-se os procedimentos metodológicos que orientaram a execução da pesquisa; após esse momento, há uma exposição e uma elaboração dos dados e uma breve descrição de suas potencialidades; 
finaliza, por fim, com considerações sobre os achados do trabalho, apontando para a importância de trabalhos dessa natureza para a área da sociologia da cultura, da arte e da literatura como um tipo de "sociologia da recepção".

\section{APORTES TEÓRICOS PARA UMA SOCIOLOGIA DA RECEPÇÃO}

Autores como Antonio Candido (2006) e Hans Robert Jauss (1994) procuram, no âmbito da crítica e teoria literária, enfatizar elementos como a trajetória social de um(a) artista, o contexto de sua produção e recepção e a própria historicidade em torno de sua obra já consumada, assumindo a importância de uma crítica que se detenha tanto na recepção das obras quanto em seus aspectos formais. Do mesmo modo, no âmbito da sociologia da cultura, como argumentam Elide R. Bastos e André Botelho (2010), há uma área que se dedica particularmente à reflexão sobre os intelectuais, conjugando as relações existentes entre seu contexto de produção e o alcance de suas obras sob uma perspectiva sociológica.

O trabalho que aqui se apresenta procura abranger uma síntese dessas distintas posições teóricas, concentrando-se particularmente na recepção da obra de um intelectual brasileiro nos próprios meios intelectuais de produção do conhecimento, abordando, desse modo, características "formais" relacionadas a esse meio de produção/recepção, bem como as formulações dessa recepção, compreendida aqui pelas noções de uso e de apropriações da obra. Se Jauss (1994) advoga por uma estética da recepção, a proposta aqui defendida estaria próxima a uma "sociologia da recepção", explorando aspectos que não foram colocados no horizonte de expectativas do crítico alemão mas que nos habilitam a pensá-los sociologicamente.

Nossa abordagem teórica irá se apoiar em duas contribuições: primeiramente, a própria organização analítica efetuada por Antonio Candido em suas obras mestras, em que a busca pela constituição sócio-histórica de um sistema literário se dá através da configuração de uma tríade “indissolúvel” - autor-obra-público que, retroalimentando-se, possibilitam estabilizar as relações e prover autonomia relativa a tal sistema (CANDIDO, 2000; 2006). Tentando ultrapassar interpretações unilaterais e mecanicistas da relação entre arte e sociedade, Candido leva adiante uma abordagem dialética que supera as limitações daquelas interpretações. Assim é que "a arte é social nos dois sentidos: depende da ação de fatores do meio, que se exprimem na obra em graus diversos de sublimação; e produz sobre os indivíduos um efeito prático, modificando a sua conduta e concepção do mundo" (CANDIDO, 2006, p. 30). Desse modo, a busca pelos "fatores socioculturais" que concretamente informam a obra artística não pode obscurecer a atenção à repercussão que a obra provoca em seu meio, 
pois, sociologicamente ao menos, ela só está acabada no momento em que repercute e atua, porque (...) a arte é um sistema simbólico de comunicação inter-humana, e todo processo de comunicação pressupõe um comunicante, no caso o artista; um comunicado, ou seja, a obra; um comunicando, que é o público a que se dirige; graças a isso define-se o quarto elemento do processo, isto é, o seu efeito (CANDIDO, 2006, p. 31).

Este esquema teórico já foi utilizado por outros pesquisadores para dar conta de fenômenos não-estritamente literários (BASTOS, 2013), e aqui aproveitamos o ensejo para avaliar o modo de apropriação da própria obra de Antonio Candido. Nosso foco, portanto, será perceber como o crítico literário é apropriado pelo público de pesquisadores em Ciências Sociais, deste modo levando a insights sobre a apropriação, por parte deste público, da obra daquele autor.

Em um segundo ponto de apoio teórico, temos a corrente da estética da recepção salientando a importância da interação entre receptor e autor e da dimensão da recepção e do efeito da obra para se construir uma historiografia literária (JAUSS, 1994). A importância do leitor da obra é salientada, já que, destinatário desta, ele possui um papel ativo, tanto estético quanto histórico, ligado ao horizonte de expectativas estabelecido. Se, por um lado, o leitor irá avaliar a obra a partir de uma comparação com outras obras disponíveis e lidas, há, por outro, uma trajetória de leitura entre diferentes gerações de receptores - uma série histórica de leitores -, que provê um significado histórico à obra. Essa posição permite reatar "o fio que liga o fenômeno passado à experiência presente, fio este que o historicismo rompera" (JAUSS, 1994, p. 23) ao interpretar as obras artísticas como conectadas a um espírito de época específico, delimitado e compreensível apenas em seus próprios termos.

Busca-se, assim, o processo de recepção ativa na qual o leitor e o crítico têm papel fundamental no contexto da experiência dinâmica da literatura. Determinar o horizonte de expectativas estabelecido, ou seja, as coordenadas hermenêuticas - a "partitura voltada para a ressonância sempre renovada da leitura” (JAUSS, 1994, p. 25) - em que obras literárias são recepcionadas é, portanto, central. Adicionalmente, o impacto que as obras têm na transformação desse horizonte de expectativas se mostra como um eixo heurístico para evidenciar a evolução literária, sem recair em teleologismos (JAUSS, 1994). Aqui iremos apontar, de maneira mais específica, para os efeitos e usos da obra de Antonio Candido no âmbito da produção acadêmica voltada para os congressos da área. 


\section{PROCEDIMENTOS METODOLÓGICOS}

Os procedimentos metodológicos adotados para essa pesquisa inspiraram-se nos critérios e nas variáveis estabelecidas por Rafael Sampaio et al (2018), particularmente utilizados para a organização e para o tratamento do corpus empírico. Procedeu-se, desse modo, a uma pesquisa bibliográfica de caráter quali-quantitativo que procurou mapear a produção acadêmica publicada em anais e portais de três congressos brasileiros tradicionais na área de Ciências Sociais: Congressos da Sociedade Brasileira de Sociologia (SBS), Encontros Anuais da Associação Nacional de Pós-Graduação e Pesquisa em Ciências Sociais (Anpocs) e Reuniões da Associação Brasileira de Antropologia (ABA). Os documentos que compuseram o material empírico passaram por um processo de coleta, no qual foram definidos critérios de inclusão e exclusão de documentos; após essa organização do corpus, realizamos um tratamento de classificação dos documentos e um processo de codificação analítica da base de dados.

Os documentos foram coletados nos anais disponíveis on-line dos três congressos mencionados anteriormente ${ }^{3}$ com um espectro temporal estabelecido entre 2005 e 2017. Para organizar a seleção e afunilar os documentos que compuseram a base de dados, foram utilizados dois critérios metodológicos que se configuraram como dois filtros para seleção dos documentos disponíveis. Assim, o $1^{\mathrm{o}}$ filtro está voltado para a seleção dos sub-eventos que comporiam a base de dados e, em seguida, o $2^{\circ}$ filtro objetiva a seleção dos textos no interior dos sub-eventos que usam e se apropriam da obra de Antonio Candido como referência.

$1^{o}$ filtro: Foram selecionados todos os sub-eventos ${ }^{4}$ cujos títulos apresentassem pelo menos um dos três termos seguintes: cultura, arte ou literatura. Após esse momento, os subeventos e sua produção foram avaliados a partir da sua pertinência segundo os interesses e a área de concentração desta pesquisa. Desse modo, foram excluídas modalidades cujo título fosse, por exemplo, ciberpolítica, ciberativismo e cibercultura, pois, ainda que apresente a palavra cultura, esta não possuía interface com a produção acadêmica de Antonio Candido. Nessa etapa, foram selecionados 22 sub-eventos que contém, por sua vez, os documentos das respectivas apresentações propostas.

$2^{o}$ filtro: No âmbito desses 22 sub-eventos, foram encontrados, no total, 1149 documentos. O segundo filtro, contudo, afunila esse número utilizando por critério a seleção dos documentos que façam referência nominal ou bibliográfica explícita a Antonio Candido e

\footnotetext{
${ }^{3}$ Os anais dos eventos (1) SBS, (2) Anpocs e (3) ABA estão disponíveis, respectivamente, nos links a seguir: (1) http://www.sbsociologia.com.br/2017/index.php?formulario=congressos\&metodo=0\&id=3; http://www.anpocs.com/index.php/encontros/encontros-anteriores; (3) http://www.portal.abant.org.br/?s=anais. 4 "Sub-eventos" são modalidades de organização da apresentação de trabalhos acadêmicos em congressos científicos, tais como conferẽncias, sessões, simpósios, mesas redondas, colóquios, fóruns, grupos de trabalho, etc.
} 
sua obra, consolidando, assim, os documentos que irão compor a base de dados a ser tratada e analisada para produção dos dados discutidos na próxima sessão.

Aplicados tais filtros de seleção, foram encontrados, no total, 56 documentos para composição da base de dados separados segundos os três eventos analisados (tabela 1).

Tabela 1 - Número total de documentos por ano (2005-2017) em relação aos três eventos

\begin{tabular}{c|c|c|c|c|c}
\hline Ano & ABA* & Anpocs & \multicolumn{2}{l}{ SBS* } & \multicolumn{2}{c}{ Total } \\
\hline 2005 & - & 0 & 2 & 2 & $4 \%$ \\
\hline 2006 & 0 & 0 & - & 0 & $0 \%$ \\
\hline 2007 & - & 1 & 7 & 8 & $14 \%$ \\
\hline 2008 & 2 & 0 & - & 2 & $4 \%$ \\
\hline 2009 & - & 0 & 9 & 9 & $16 \%$ \\
\hline 2010 & 4 & 5 & - & 9 & $16 \%$ \\
\hline 2011 & - & 0 & 6 & 6 & $11 \%$ \\
\hline 2012 & 1 & 1 & - & 2 & $4 \%$ \\
\hline 2013 & - & 3 & 0 & 3 & $5 \%$ \\
\hline 2014 & 2 & 7 & - & 9 & $16 \%$ \\
\hline 2015 & - & 4 & 1 & 5 & $9 \%$ \\
\hline 2016 & 0 & 0 & - & 0 & $0 \%$ \\
\hline 2017 & - & 1 & 0 & 1 & $2 \%$ \\
\hline Total geral & $9(16 \%)$ & $22(39 \%)$ & $25(45 \%)$ & 56 & $100 \%$ \\
\hline
\end{tabular}

* Eventos bianuais.

Fonte: Base de dados, 2018. Elaboração própria

\section{RECEPÇÃO ACADÊMICA DE ANTONIO CANDIDO EM TRÊS CONGRESSOS DE CIÊNCIAS SOCIAIS}

Delimitado esse corpus, foram identificados os trechos dos documentos que faziam referência a Candido. Esses trechos foram posteriormente analisados e codificados em um programa de metodologia qualitativa (Atlas.ti), como veremos abaixo. Para tratamento, classificação e codificação dos documentos foram forjados dois grupos de variáveis: o primeiro de (1) características autorais, institucionais e temáticas; e o outro de (2) características hermenêuticas, particularmente referentes aos eixos analíticos dos usos e apropriações da obra de Candido.

Os dois grupos de variáveis contemplam a argumentação levada adiante por Candido (2000, 2006) na medida em que reafirma a noção de que fatores sociológicos externos às obras e aos 
documentos condicionam e são influenciados por fatores internos (formais) de caráter estético e/ou teórico, compreendendo os dois âmbitos fundamentais de uma produção literária, científica e intelectual: a relação entre texto e contexto, demarcando sua tênue fronteira analítica e seu caráter empiricamente indissolúvel. Essa "redução estrutural” reitera que autor-obra-público só existem situados em um contexto sócio-histórico e que essa tríade, do mesmo modo, exerce influência sobre seu contexto. Com base nesse pressuposto, para os procedimentos de análise desta pesquisa foi feita uma primeira leitura dos documentos que possibilitou perceber os diferentes modos de apropriação de Candido e sua obra, que foram tipificados a partir de 5 eixos de apropriação. Uma segunda leitura permitiu sobrepesar a primeira e codificar esses trechos a partir dos diferentes modos de apropriação.

Esse procedimento teórico-metodológico, contudo, necessita de um parêntesis, já que é fundamental diferenciar qualitativamente documentos históricos e bibliográficos de textos literários, posicionando a consequência disso para escolhas metodológicas que distinguem uma análise documental/bibliográfica de uma crítica literária como procedimentos distintos que demarcam a complexidade e a autonomia parcial do texto literário enquanto objeto de análise. A proposta que se assume neste trabalho inverte a lógica comum das Ciências Humanas e Sociais (CAMILOTI, NAXARA, 2009): ao invés de tratar textos literários estritamente como documentos históricos, busca-se em teóricos literários consagrados, como Candido (2000, 2006) e Jauss (1994), um modo de subsidiar uma análise documental/bibliográfica de caráter sociológico, o que se expõe aqui na distinção de grupos de variáveis e eixos de análise forjados para levar adiante a análise. Desse modo, a historicidade da leitura e da apropriação dos textos e ideias de Candido é mantida para além do caráter representativo de uma época: os próprios textos e as ideias que veiculam são forjadores do contexto de recepção da obra de Candido.

\section{a) Descrição categórica da produção acadêmica sobre Antonio Candido}

No que se refere às características autorais, institucionais e temáticas dos documentos, aqui situadas analiticamente em um polo de atributos sociais dos autores dos documentos analisados, avaliamos as variáveis: gênero dos autores e coautores, instituições de vinculação, região do país em que se encontram tais instituições, grupos temáticos de classificação e as obras de Candido mais referenciadas.

Quanto à variável gênero (tabela 2), o total de documentos analisados no âmbito do espectro temporal em relação aos três eventos apresenta um equilíbrio percentual, tendo distribuição autoral de $49 \%$ de do gênero feminino e $51 \%$ do gênero masculino que mobilizam Candido em seus textos. Esse equilíbrio, contudo, não se verifica na distribuição em cada um dos eventos, de maneira que ABA e SBS apresentam maior representação estatística para o gênero feminino, enquanto no 
encontro da Anpocs há uma parcela substancialmente maior de autores do gênero masculino que mobilizam o autor.

\section{Tabela 2 - Gênero dos autores e coautores ${ }^{5}$ em relação aos três eventos}

\begin{tabular}{c|c|c|c|c}
\hline Gênero & ABA & Anpocs & SBS & Total \\
\hline Feminino & 7 & 7 & 15 & 29 \\
\hline Masculino & 2 & 17 & 11 & 30 \\
\hline Total geral & 9 & 22 & 25 & 56 \\
\hline
\end{tabular}

Fonte: Base de dados, 2018. Elaboração própria.

Em relação às instituições de vinculação (tabela 3), destaca-se a USP com $27 \%$ da vinculação institucional dos autores que mobilizam Candido em seus trabalhos, sendo esta, não coincidentemente, a instituição de formação acadêmica e de atuação profissional do crítico literário. Outra instituição em que atuou como professor foi a UNESP, que aparece em nossa pesquisa com $7 \%$ da vinculação institucional dos autores participantes dos congressos estudados. A UFRJ (13\%) e a UFPE (9\%) são instituições que também se mostram propícias a mobilizar a obra de Candido, assim como a Unicamp (7\%). Como consequência, uma grande maioria dos documentos provém de instituições localizadas na região Sudeste $(71 \%)$, com concentração no estado de São Paulo, e do Nordeste (21\%), com a pouca presença de trabalhos de instituições localizadas do Norte e Centro-Oeste, sendo especialmente notável a presença de um único trabalho vinculado a uma instituição da região Sul (tabela 4).

Tabela 3 - Instituições de vinculação dos autores dos documentos

\begin{tabular}{c|c|c|}
\hline Instituição & Quantidade & $\%$ \\
\hline USP & 15 & $27 \%$ \\
\hline UFRJ & 7 & $13 \%$ \\
\hline UFPE & 5 & $9 \%$ \\
\hline UNESP & 4 & $7 \%$ \\
\hline Unicamp & 4 & $7 \%$ \\
\hline UERJ & 3 & $5 \%$ \\
\hline PUCSP & 2 & $4 \%$ \\
\hline UFAM & 2 & $4 \%$ \\
\hline UFC & 2 & $4 \%$ \\
\hline Outras & 12 & $24 \%$ \\
\hline Total geral & 56 & $100 \%$ \\
\hline
\end{tabular}

Fonte: Base de dados, 2018. Elaboração própria

\footnotetext{
${ }^{5}$ Dentre os 56 documentos que compõem nossa base de dados, 3 deles apresentam autor e coautor, sendo discriminados na tabela, que traz um total geral de 59 autores e coautores.
} 


\section{Tabela 4 - Região das instituições de vinculação dos autores dos documentos}

\begin{tabular}{c|c|c}
\hline $\begin{array}{c}\text { Região do } \\
\text { país }\end{array}$ & Quantidade & $\%$ \\
\hline Sudeste & 40 & $71 \%$ \\
\hline Nordeste & 12 & $21 \%$ \\
\hline Norte & 2 & $4 \%$ \\
\hline Centro-Oeste & 1 & $2 \%$ \\
\hline Sul & 1 & $2 \%$ \\
\hline Total geral & 56 & $100 \%$ \\
\hline
\end{tabular}

Fonte: Base de dados, 2018. Elaboração própria.

Para além de uma dimensão autoral e institucional, foi realizada uma organização dos documentos em três grandes temas com base em seus títulos, organizando os elementos de concentração temática dos artigos avaliados (tabela 5): Sociologia da Literatura e da Arte, que alcança 59\% da temática das produções que mobilizam Candido; Cultura e cultura caipira, com $23 \%$ das produções; e Pensamento Social Brasileiro, com 18\%. As três categorias remetem à caracterização feita por Peirano (1992) já mencionada na introdução, sendo a primeira diretamente associada à produção de Candido enquanto crítico literário, a segunda à sua tese Os Parceiros do Rio Bonito, obra de caráter antropológico, e a terceira a uma interpretação sociológica do pensamento social brasileiro em emergência entre o fim do século XIX e início do século XX. Estes três grandes temas apontam para o pluralismo, ao mesmo tempo, de pesquisadores sobre distintos temas que mobilizam Candido e para a própria pluralidade de sua obra, o que fica explicitado nas citações (tabela 6) e nas apropriações (tabela 7) de sua obra, embora sobressaiam suas obras e sua faceta como crítico e teórico da Literatura.

\section{Tabela 5 - Organização temática dos documentos a partir dos títulos}

\begin{tabular}{c|c|c|c|c|}
\hline Categoria de classificação & ABA & Anpocs & SBS & Total \\
\hline Sociologia da Literatura e da Arte & 5 & 10 & 18 & 33 \\
\hline Cultura e Cultura Caipira & 4 & 3 & 6 & 13 \\
\hline Pensamento Social Brasileiro & 0 & 9 & 1 & 10 \\
\hline Total geral & 9 & 22 & 25 & 56 \\
\hline
\end{tabular}

Fonte: Base de dados, 2018. Elaboração própria.

Encontramos, nos artigos compilados, referências a 27 obras e artigos de Antonio Candido. As suas obras mais frequentemente citadas são Literatura e Sociedade (26\%) e Formação da Literatura Brasileira (16\%), seguidas de A Educação Pela Noite (9\%) e Os 
Parceiros do Rio Bonito (8\%). De maneira menos frequente temos uma série de obras e artigos que evidenciam que a apropriação de Antonio Candido não se encontra concentrada em poucas obras, ainda que algumas sejam mais referenciadas que outras. O padrão de citação das obras, em sua respectiva frequência percentual, segue a mesma lógica da organização temática (tabela 5), cabendo às três primeiras obras mais citadas uma concentração na área de Crítica Literária e Sociologia da Literatura, seguidas de obras concentradas na área de Antropologia (Cultura e cultura caipira, no eixo de nossa organização temática) e artigos e ensaios de caráter sociológico sobre Pensamento Social Brasileiro.

Tabela 6 - Citações das Obras de Antonio Candido

\begin{tabular}{c|c|c|}
\hline Obra citada & Citações & $\%$ \\
\hline Literatura e Sociedade & 20 & $26 \%$ \\
\hline Formação da Literatura Brasileira & 12 & $16 \%$ \\
\hline A educação pela noite & 7 & $9 \%$ \\
\hline Os parceiros do rio bonito & 6 & $8 \%$ \\
\hline A personagem de ficção & 2 & $3 \%$ \\
\hline A Sociologia no Brasil (Tempo Social) & 2 & $3 \%$ \\
\hline Dialética da malandragem & 2 & $3 \%$ \\
\hline Literatura e Subdesenvolvimento & 2 & $3 \%$ \\
\hline O direito à Literatura/Vários escritos & 2 & $3 \%$ \\
\hline O discurso e a cidade & 2 & $3 \%$ \\
\hline O estudo analítico do poema & 2 & $3 \%$ \\
\hline Sergio Milliet, crítico & 2 & $3 \%$ \\
\hline Outras & 15 & $20 \%$ \\
\hline Total geral & 76 & $100 \%$ \\
\hline
\end{tabular}

Fonte: Base de dados, 2018. Elaboração própria.

Ainda que não seja possível generalizar tais resultados como características gerais de autores e instituições da área de Ciências Sociais que mobilizam Antonio Candido em suas produções, tendo em vista que o recorte por evento e a delimitação de um espectro temporal não nos permite uma inferência causal ampla, os dados apresentam um panorama parcial e preliminar, contudo passível de discussões profícuas no que se refere à mobilização sociológica do campo acadêmico das Ciências Sociais quanto ao crítico literário aqui, ao mesmo tempo, analisado e mobilizado teoricamente.

Nesse sentido, com base nos dados produzidos, é possível sustentar que entre os anos de 2005 e 2017, no âmbito dos três eventos analisados, as produções que mobilizam Antonio Candido em suas referências se dão de maneira equilibrada entre autores do gênero masculino 
e feminino (tabela 2), concentrados predominantemente na região Sudeste e, subsidiariamente, Nordeste (tabela 4), com destaque para vinculação às instituições do estado de São Paulo, como USP, UNESP e Unicamp (tabela 3).

Em relação aos aspectos temáticos e referência às obras de Candido, grande parte das produções se vinculam de maneira fundamental ao campo da Sociologia da Literatura e da Arte (59\% das produções) e, em menor proporção, aos campos da Cultura e Cultura Caipira e do Pensamento Social Brasileiro (tabela 5). As obras Literatura e Sociedade e Formação da Literatura Brasileira são as mais referenciadas, totalizando $42 \%$ das citações na base compilada (tabela 6).

\section{b) Características hermenêuticas: Usos e apropriações}

A leitura dos artigos que compõem nossa base de dados permitiu ir além da organização temática e institucional da produção e da constatação das citações bibliográficas da obra de Antonio Candido. Após uma leitura dos textos, as diferentes modalidades de uso e apropriações de sua obra foram classificadas a partir de cinco eixos de análise que não são mutuamente excludentes, podendo haver sobreposição, servindo a uma delimitação do padrão dos usos e apropriações de Candido e sua obra no campo acadêmico brasileiro:

Apropriação analítica: trata-se de um uso no qual as análises produzidas por Antonio Candido sobre temas, obras, períodos históricos e autores diversos são utilizados como ponto de apoio pelos autores no sentido de levar adiante seu argumento, em grande parte endossando e estabilizando determinadas interpretações. Neste sentido, foram encontrados textos que se apoiam na análise de Candido sobre: o impacto da Revolução de 1930 no campo cultural nacional; a emergência da sociologia no Brasil; movimentos artísticos nacionais, como Romantismo e Modernismo; escritores e obras literárias diversos.

Apropriação teórica: uso explícito de conceitos e categorias de análise forjadas por ou remetidas a Antonio Candido. O uso de conceitos como "redução estrutural", "sistema literário", "dialética do cosmopolitismo e do localismo" possibilitam aos autores a análise de objetos e temáticas diversos partindo destas noções forjadas por Candido. Esse uso significa, portanto, não o uso de análises empreendidas pelo crítico literário, mas de um desdobramento analítico efetuado com recurso a categorias conceituais por ele elaboradas. 
Apropriação heurística: adoção explícita de uma abordagem do objeto de pesquisa que marca uma busca por aspectos heurísticos concebidos por Antonio Candido, promovendo uma atitude de aproximação entre crítica estético-literária e a análise sociológica, de forma integrativa ou dialética. A delimitação metodológica em que se busca analisar a obra em seu contexto e o impacto da obra em seu ambiente, por exemplo, revela essa abordagem integrativa.

$\checkmark$ Menções biográficas e/ou históricas: referência à participação de Antonio Candido em eventos que são histórica e/ou sociologicamente relevantes: participação no grupo Clima, na geração que institucionaliza as Ciências Sociais e sua influência em outros eventos culturais relevantes.

Exegese de Antonio Candido e sua obra: análises sobre a trajetória de pesquisa e de crítica de Antonio Candido, na qual Candido e sua obra são tomados como objeto de análise e de pesquisa, não servindo como suporte para análises de outros temas/assuntos.

Como podemos ver na tabela 7 , mais da metade $(61 \%)$ dos documentos se apoiam em análises de Candido, enquanto cerca de um terço (34\%) utiliza conceitos e noções forjadas pelo crítico uspiano. Há também cerca de um quarto dos documentos que se apropriam heuristicamente de sua proposta e, na mesma proporção, artigos que fazem menções biográficas ou históricas de sua pessoa. Uma porção pequena de apenas dois artigos trabalhou no sentido de construir uma exegese interpretativa de sua obra. No Gráfico 1 podemos ver como se distribui temporalmente as modalidades de apropriação da obra de Candido: o biênio 20092010 foi particularmente profícuo em usos de Candido e sua obra, com grande quantidade de apropriações analíticas, teóricas e heurísticas; em contraposição, o biênio 2005-2006 teve apenas um caso singular de apropriação teórica de sua obra. De maneira geral, não é possível perceber um padrão temporalmente estabelecido de predominância ou de crescimento de modalidades de apropriação específicas.

Tabela 7 - Modalidades de Apropriação da Obra de Antonio Candido

\begin{tabular}{c|c|c|c|c|c|c|c|c}
\hline Categorias & \multicolumn{2}{|c|}{ ABA } & \multicolumn{2}{c|}{ ANPOCS } & \multicolumn{2}{c}{ SBS } & \multicolumn{2}{c}{ Total } \\
\hline Apropriação analítica & 5 & $56 \%$ & 14 & $64 \%$ & 15 & $60 \%$ & 34 & $61 \%$ \\
\hline Apropriação teórica & 2 & $22 \%$ & 7 & $32 \%$ & 10 & $40 \%$ & 19 & $34 \%$ \\
\hline Apropriação heurística & 1 & $11 \%$ & 5 & $23 \%$ & 7 & $28 \%$ & 13 & $23 \%$ \\
\hline Menções biográficas & 4 & $44 \%$ & 5 & $23 \%$ & 4 & $16 \%$ & 13 & $23 \%$ \\
\hline Exegese da obra & 0 & $0 \%$ & 1 & $5 \%$ & 1 & $4 \%$ & 2 & $4 \%$ \\
\hline
\end{tabular}




\begin{tabular}{|l|l|l|l|l|l|l|l|l}
\hline Total de documentos & 9 & $100 \%$ & 22 & $100 \%$ & 25 & $100 \%$ & 56 & $100 \%$ \\
\hline
\end{tabular}

Fonte: Base de dados, 2018. Elaboração própria.

\section{Gráfico 1 - Modalidades de apropriação da Obra de Antonio Candido, por biênio}

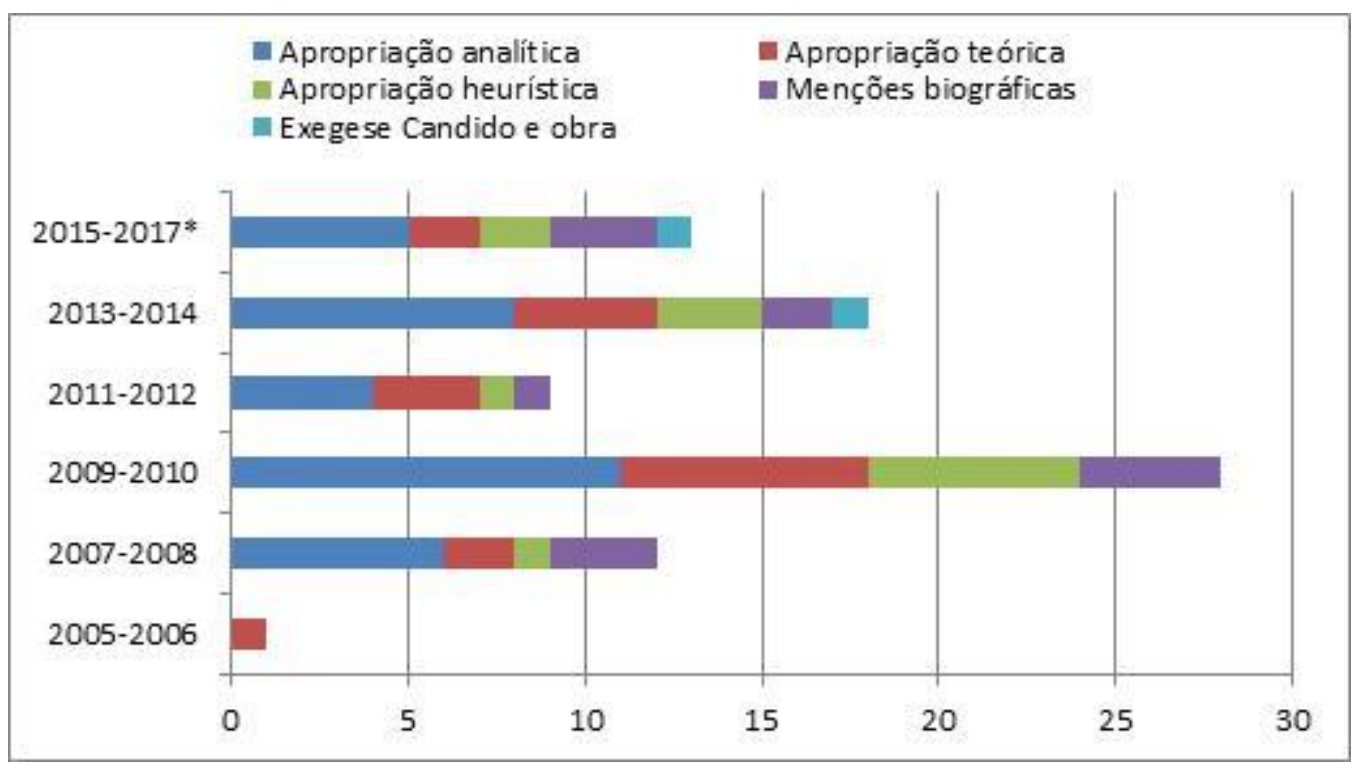

Fonte: Base de dados, 2018. Elaboração própria.

Tendo em vista que a modalidade analítica de apropriação foi a mais observada, procedemos a uma subdivisão a fim de compreender quais são os tipos de análises de Candido que são mais mobilizadas pelos pesquisadores. Na tabela 8 podemos ver a distribuição de uma subcodificação da apropriação analítica, diferenciada por congresso. As análises englobadas no âmbito da subcategoria "Teoria e Crítica Literária" se referem a interpretações que Candido realizou sobre escritores, tais como João Cabral de Melo Neto, Carlos Drummond de Andrade e Joseph Conrad, bem como menções a textos clássicos no âmbito da Teoria e Crítica Literária, como Literatura e Subdesenvolvimento e $O$ direito à Literatura. No âmbito da subcategoria "Movimentos Artísticos e Culturais", trata-se de análises relativas a movimentos artísticos e culturais brasileiros, em especial ao Modernismo Paulista e à Revolução de 30; a categoria "Pensamento Social" sinaliza as análises voltadas à constituição da Sociologia no Brasil, em especial na figura de autores como Sérgio Buarque de Hollanda, Gilberto Freyre e Caio Prado Jr. Por fim, a modalidade "Cultura Caipira" refere-se aos argumentos elaborados por Antonio Candido em sua tese de doutoramento em Ciências Sociais.

Percebe-se preponderância relativa das análises literárias e artísticas, ainda que suas interpretações sobre a formação da sociologia no Brasil e suas considerações sobre a cultura caipira paulista sejam bastante mobilizadas. Há evidências de uma ausência de debate, na ABA, sobre a 
temática de Pensamento Social, que se mostra central no âmbito da Anpocs. As análises sobre Teoria e Crítica Literária são particularmente presentes na SBS, enquanto as temáticas de Movimentos Artísticos e Culturais e de Cultura Caipira aparecem proporcionalmente destacadas na ABA.

Tabela 8 - Modalidades de apropriação analítica da obra de Antonio Candido, por congresso

\begin{tabular}{c|c|c|c|c|c|c|c|c}
\hline Subcategorias & \multicolumn{2}{|c|}{ ABA } & \multicolumn{2}{c|}{ ANPOCS } & \multicolumn{2}{c}{ SBS } & \multicolumn{3}{c}{ Total } \\
\hline Teoria e Crítica Literária & 1 & $20 \%$ & 3 & $21 \%$ & 6 & $40 \%$ & 10 & $29 \%$ \\
\hline Movimentos artísticos e culturais & 2 & $40 \%$ & 3 & $21 \%$ & 4 & $27 \%$ & 9 & $26 \%$ \\
\hline Pensamento Social & 0 & $0 \%$ & 6 & $43 \%$ & 2 & $13 \%$ & 8 & $24 \%$ \\
\hline Cultura Caipira & 2 & $40 \%$ & 2 & $14 \%$ & 3 & $20 \%$ & 7 & $21 \%$ \\
\hline Total geral & 5 & $100 \%$ & 14 & $100 \%$ & 15 & $100 \%$ & 34 & $100 \%$ \\
\hline
\end{tabular}

Fonte: Base de dados, 2018. Elaboração própria.

\section{CONSIDERAÇÕES FINAIS}

A partir dos dados apresentados podemos elaborar alguns argumentos em relação aos modos de apropriação de Antonio Candido e sua obra nos congressos de Ciências Sociais aqui analisados. Primeiramente, trata-se de um autor que é lido e debatido em áreas diversas das Ciências Sociais, ainda que com menor inserção no campo da Antropologia, e que tem sido mobilizado de maneira relativamente constante ao longo dos últimos 13 anos.

Sua produção analítica, interpretando movimentos culturais e literários, livros, escritores e épocas históricas marcam sua referência como uma espécie de intelectual que provê interpretações diversas, as quais auxiliam os pesquisadores a conformarem um ponto de apoio analítico para perseguirem seus objetivos de pesquisa. $\mathrm{O}$ arcabouço teórico de sua obra também é bastante mobilizado, possibilitando aos pesquisadores significar e produzir conhecimentos a partir de sua utilização no processo de investigação. Tal acontece também com o modo heurístico e integrativo de análise sociológica da obra cultural, que permite aos pesquisadores posicionarem-se, de modo dialético, perante as tensões fundamentais da crítica sociológica (tensões entre indivíduo-sociedade, entre texto-contexto, entre obra-sociedade).

Essa modalidade aponta para o modo como Antonio Candido "resolveu" um dos problemas fundamentais da teoria social tal qual colocado por Jeffrey Alexander (1987) em torno da tensão entre estrutura e agência. Parte dos documentos que aqui identificamos se referem explicitamente a esta questão, o que evidencia a importância de Candido na resolução 
deste problema tal qual ele aparece no âmbito da sociologia da literatura em interface com a crítica literária, qual seja, o problema da relação entre texto e contexto, entre artista e público, entre indivíduo e sociedade. Tal é o ponto que, ressaltado por Leopoldo Waizbort (2002), como aquele que constitui o "arco amplo" que integra a produção intelectual de Antonio Candido desde o início de sua carreira até o fim do século passado. As menções biográficas reivindicam o testemunho de Antonio Candido enquanto partícipe e agenciador de momentos culturais relevantes da vida social e cultural nacional e, particularmente, paulistanos. Os trabalhos exegéticos se configuram como pouco frequentes, ainda que sinalizem a centralidade de sua obra para o campo de debate como um todo.

Ainda que a análise aqui empreendida abranja certo lapso temporal, sua configuração é em grande parte sincrônica, já que não identificamos um acontecimento que tenha sido capaz de alterar o horizonte de expectativas estabelecido (JAUSS, 1994), tendo em vista a regularidade observada com que a obra de Candido foi apropriada ao longo dos últimos anos. Assim, a série histórica de leitores permanece como um ponto a ser construído futuramente. No entanto, foi possível perceber uma pluralidade nos diferentes horizontes de expectativas que recebem a obra do autor, devido à diferenciação dos modos de apropriação entre os diferentes congressos.

A partir dos dados e das análises construídas, é possível apontar algumas possibilidades para um futuro programa de pesquisa, no sentido de investigar, com um espectro temporal mais alargado, o estabelecimento e trajetória do horizonte de expectativas colocado em torno da obra de Antonio Candido e outros intelectuais, além de suas linhagens teóricas. Esta pesquisa poderia apontar uma tensão comparativa com outras correntes no âmbito da sociologia brasileira da cultura e da arte, quais sejam, a corrente americana (Gilberto Velho e Howard Becker) e a corrente francesa (Sérgio Miceli e Renato Ortiz), em contraste com uma perspectiva germânica (Sérgio Buarque de Holanda e Antonio Candido), seguindo as pistas de Leopoldo Waizbort (2002)

As futuras investigações podem abranger congressos da área de Letras e Literatura para aprofundar essa conformação múltipla das distintas correntes teóricas e também da própria apropriação da obra de Candido. Tal projeto poderia contribuir para o estabelecimento de uma agenda de exploração investigativa no âmbito de uma sociologia da recepção que fosse além de uma compreensão do autor em sua contemporaneidade, favorecendo a apreensão analítica dos modos de apropriação de sua obra que se desdobrassem ao longo do tempo histórico e que são possíveis de uma investigação mais aprofundada. 


\section{REFERÊNCIAS BIBLIOGRÁFICAS}

ALEXANDER, J. O Novo Movimento Teórico. Revista Brasileira de Ciências Sociais, v. 02, n. $\quad 04, \quad$ p. $05-28, \quad 1987 . \quad$ Disponível em:

http://www.anpocs.org.br/portal/publicacoes/rbcs_00_04/rbcs04_01.htm, acesso em 01 de mai. 2019.

BASTOS, E. R.; BOTELHO, A. Para uma sociologia dos intelectuais. Dados, Rio de Janeiro, v. 53, n. 4, p. 889-919, 2010. Disponível em: http://www.scielo.br/pdf/dados/v53n4/a04v53n4.pdf, acesso em 01 de mai. 2019.

BASTOS, E. R. A construção do debate sociológico no Brasil. Idéias - Revista do Instituto de Filosofia e Ciências Humanas, v. 1, p. 287-300, 2013. Disponível em: https://periodicos.sbu.unicamp.br/ojs/index.php/ideias/article/view/8649424/15979, acesso em 01 de mai. 2019.

BECKER, H. S. Mundos da Arte. Edição Comemorativa do 25 aniversário. Revista e Aumentada. Lisboa: Livros Horizonte, 2010.

BOURDIEU, P. As Regras da Arte: Gênese e Estrutura do Campo Literário. São Paulo: Companhia das Letras, 1996.

BOURDIEU, P. Les conditions sociales de la circulation internationale des idées. Actes de la recherche en sciences sociales, v. 5, n. 145, p. 3-8, 2002. Disponível em:

https://www.cairn.info/revue-actes-de-la-recherche-en-sciences-sociales-2002-5-page-

3.htm, acesso em 01 de mai. 2019.

BOURDIEU, P. A Distinção: Crítica Social do Julgamento. São Paulo: Edusp, 2006.

CAMILOTTI, Virgínia; NAXARA, Márcia Regina C. História e Literatura: fontes literárias na produção historiográfica recente no Brasil. História: Questões \& Debates, Editora UFPR:

Curitiba, n. 50, p. 15-49, 2009. Disponível em: https://revistas.ufpr.br/historia/article/view/15670/10411, acesso em 01 de mai. 2019.

CANDIDO, A. Formação da Literatura Brasileira: momentos decisivos. 6a edição. Belo Horizonte: Editora Itatiaia, 2000.

CANDIDO, A. Literatura e Sociedade. $9^{\text {a }}$ edição revista pelo autor. Rio de Janeiro: Ouro Sobre Azul, 2006.

GEERTZ, C. A Arte como Sistema Cultural. In: O Saber Local: novos ensaios em antropologia interpretativa. Petrópolis: Vozes, 1997.

JACKSON, L. C. Antonio Candido: crítica e sociologia da literatura. In: BOTELHO, André; SCHWARCZ, Lilia M. Um Enigma Chamado Brasil: 29 intérpretes e um país. São Paulo: Companhia das Letras, 2009.

JAUSS, H. R. A História da Literatura como Provocação à Teoria Literária. São Paulo: Editora Ática, 1994.

MANNHEIM, K. The Problem of a Sociology of Knowledge. In: MANNHEIM, K.; KECSKEMETI, P. Essays on the Sociology of Knowledge. New York, Oxford University Press, 1952, pp. 134-190.

PEIRANO, M. Uma antropologia no plural: três experiências contemporâneas. Brasília: Universidade de Brasília, 1992.

PONTES, H. Destinos mistos: os críticos do grupo Clima em São Paulo (1940-68). São Paulo: Companhia das Letras, 1998.

SAMPAIO, R. et al. Ciberpolítica, ciberativismo e cibercultura: uma análise dos papers apresentados no grupo de trabalho da Anpocs. BIB, São Paulo, n. 85, 2018, pp. 126-147.

Disponível em: $\quad$ https://www.anpocs.com/index.php/bib-pt/bib-85/11112-ciberpolitica- 
ciberativismo-e-cibercultura-uma-analise-dos-papers-apresentados-no-grupo-de-trabalhoda-anpocs/file, acesso em 01 de mai. 2019.

SANSEVERINO, A. M. O poeta e o crítico, diálogo entre Drummond e Candido. Revista Letras, Curitiba, n. 74, p. 101-116, jan./abr, 2008. Editora UFPR. Disponível em: https://revistas.ufpr.br/letras/article/view/10952/10557, acesso em 01 de mai. 2019.

SANTOS, Luiz Antonio C. A radicalidade de Os Parceiros do Rio Bonito. Revista Brasileira de Ciências Sociais, São Paulo, v. 17, n. 49, p. 31-38, 2002. Disponível em: http://www.scielo.br/pdf/rbcsoc/v17n49/a03v1749.pdf, acesso em 01 de mai. 2019.

WAIZBORT, L. Esquema (Parcial) de Antonio Candido. Novos Estudos, v. 3, n. 64, p. 177$188,2002$. 